\title{
Entering a new era of Predictive Medicine in Rhinology
}

The June 2018 issue of Rhinology paves the way for real-life implementation of Precision Medicine in Rhinology, with Predictive Medicine in the center of attention. Physicians treating patients with rhinologic disorders might find it extremely interesting to find reports on predictors of success of medical or surgical interventions.

Prediction of success of treatment is crucial to allow the patient become an active partner in the decision-making process of medical or surgical treatment. Defining the clinical phenotype of patients with chronic rhinosinusitis responding well to either revision surgery or long-term oral macrolide treatment represents a true challenge. Oakley and co-workers ${ }^{(1)}$ compared the profile of responders to oral macrolide treatment with that of non-responders and found out that low tissue and serum eosinophilia may predict a CRS phenotype that will respond well to long-term oral macrolide treatment. In spite of the relatively small patient group being studied $(n=28)$, the results might be implemented directly into daily practice. The outcomes of endoscopic polypectomy in clinic (EPIC) in comparison to endoscopic sinus surgery is the focus of report by the group of Desrosiers ${ }^{(2)}$, highlighting the short-term (3 month) benefit of both procedures, and relaunching the need to further study and position the aims and outcomes of both procedures in the future.

In the surgical context, patients with CRS and Eustachian tube dysfunction might be reassured by the knowledge that middle ear problems related to Eustachian tube dysfunction are responding well to endoscopic sinus surgery ${ }^{(3)}$. Also patients with chronic sphenoiditis undergoing a sphenoid drill out procedure can be informed about the good endoscopic and subjective outcome parameters in the majority of patients ${ }^{(4)}$, with a sphenoid drill out procedure being a valid alternative for revision sphenoidotomy.

Prediction of complication risks of surgical interventions is highly appreciated by patients and recognised as being crucial in the medico-legal context. A proper analysis of the risk of taste dysfunction after cochlear implantation is possible thanks to the report of Walliczek-Dworschak et al. ${ }^{(5)}$, including the novel finding of cochlear implant candidates exhibiting impaired taste and olfactory function preoperatively. Of note, odor detection tresholds in elderly idiopathic Parkinson patients are more impaired than the trigeminal pathway ${ }^{(6)}$, with significant differences in detection threshold between those Parkinson patients with/without good autonomy. Bucher et al. ${ }^{(7)}$ bring to the attention their stuy on the high incidence of occult cerebrospinal fluid leaks after endoscopic sinus surgery in up to $13 \%$ of patients, with the reassuring findings of lack of major impact for the patients on both short and long term. Based on a retrospective analysis of 40 patients having undergone frontal sinus obliteration for massive fronto-ethmoidal mucocoele(s) with mean follow-up of 80 months, Hansen et al. ${ }^{(8)}$ show recurrent mucocoele formation and revision rate in only $7,5 \%$. In the field of function rhinoplasty, Novoa et al. ${ }^{(9)}$ provide long-term patient satisfaction and objective data on tip projection after placement of an intercrural columellar strut graft. All of these studies highlight the huge efforts of leaders in the field of Rhinology paving the way for a better future of patients affected by rhinologic conditions.

Prediction of development of disease remains a true challenge, allowing the implementation of preventive measure in time. A unique report of the higher prevalence of CRSWNP in textile works by Veloso-Teles et al. ${ }^{\left({ }^{10}\right)}$ might strengthen the link between the occupational environment and CRSwNP, as reported previously by Hox et al. ${ }^{(11)}$.

Nasal patency measurements are subject to an ongoing quest for the best possible objective tool for quantification of flow, resistance and nasal cycle. In this context, you might find the study of Pendolino et al. ${ }^{(12)}$ and the report of the RIGA consensus conference on nasal airway function tests ${ }^{(13)}$ inspiring. Whatever diagnostic test is being applied for quantification, a detailed history and careful clinical examination remain key to success in the indication for any medical or surgical intervention.

\section{References}

1. Oakley GM, Christensen JM, Sacks R, Earls P, Harvey RJ. Characteristics of macrolide responders in persistent post-surgical rhinosinusitis. Rhinology. 2018; 2: 56: 111-117.

2. Kilty SJ, Lasso A, Mfuna-Endam L, Desrosiers MY. Case-control study of endoscopic polypectomy in clinic (EPIC) versus endoscopic sinus surgery for chronic rhinosinusitis with polyps. Rhinology. 2018; 2: 56: .155-157.

3. Maniakas A, Desrosiers MY, Asmar MH, et al. Eustachian tube symptoms are frequent in chronic rhinosinusitis and respond well to endoscopic sinus surgery. Rhinology. 2018; 2: 56: 118-121.

4. Van Zele T, Pauwels B, Dewaele F, Gevaert
P, Bachert C. Prospective study on the outcome of the sphenoid drill out procedure. Rhinology. 2018; 2: 56: 178-182.

5. Walliczek-Dworschak U, Knauer CM, Mürbe D, Mainka A, Hummel T. Analysis of taste function in patients before and after cochlear implant surgery. Rhinology. 2018; 2: 56 : 149-154. 
6. Foguem C, Lemdani M, Huart C. Parkinson disease in eldery patients: lessons from odour detection thresholds on olfactotrigeminal interaction. Rhinology. 2018; 2 56: 127-132.

7. Bucher S, Kugler A, Probst E, et al. Occurrence of occult CSF leaks during standard FESS procedures. Rhinology. 2018; 2: 56: 166-171.

8. Hansen FS, van der Poel NA, Freling NJM, Fokkens WJ. Mucocele formation after frontal sinus obliteration. Rhinology. 2018; 2: 56 : 106-110

9. Novoa E, Simmen D, Briner HR, Schlegel C Long-term results after restoring nasal tip support using auricular cartilage as an intercrural columellar strut graft: the "I-Beam" technique. Rhinology. 2018; 2: 56: 183-188.
10. Veloso-Teles R, Cerejeira R, Roque-Farinha $R$, von Buchwald $C$. Higher prevalence of nasal polyposis among textile workers: an endoscopic based and controlled study. Rhinology. 2018; 2: 56: 99-105

11. Hox V, Steelant B, Fokkens W, Nemery B, Hellings PW. Occupational upper airway disease: how work affects the nose. Allergy. 2014; 69 (3): 282-291.

12. Pendolino $A L$, Nardello $E$, Lund VJ, et al. Comparison between unilateral PNIF and rhinomanometry in the evaluation of nasal cycle. Rhinology. 2018; 2: 56: 122-125.

13. Vogt $K$, Bachmann-Harildstad G, Lintermann A, Nechyporenko A, Peters F, Wernecke KD The new agreement of the international RIGA consensus conference on nasal airway function tests. Rhinology. 2018; 2: 56

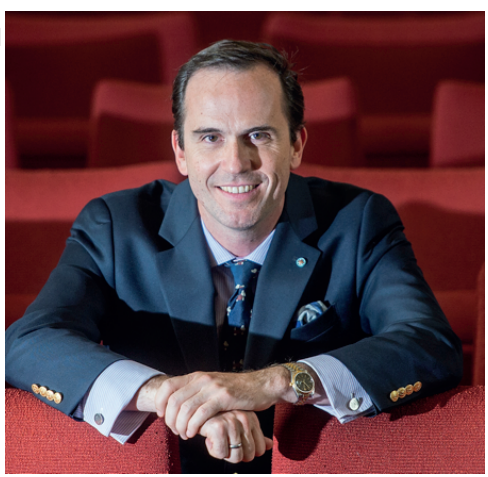

Peter W. Hellings, Associate Editor Leuven, Belgium 